\title{
Use of enoxaparin in the setting of warfarin induced calciphylaxis in an ESRD patient with a mechanical heart valve
}

Nisha Patel ${ }^{1}$, Peter Gregos ${ }^{1}$, Soniya Chandrasekhara ${ }^{1}$, and Eshan Patel $^{1}$

${ }^{1}$ New York-Presbyterian Brooklyn Methodist Hospital

August 10, 2020

\begin{abstract}
Calciphylaxis creates a challenge in anticoagulation therapy for patients with mechanical heart valves and ESRD as warfarin cannot be used. We describe our approach in using enoxaparin as an alternative for anticoagulation in a patient with a mechanical heart valve and ESRD who developed calciphylaxis from warfarin.
\end{abstract}

\section{Hosted file}

Case report- Calciphylaxis and Enoxaparin Final.pdf available at https://authorea.com/ users/350010/articles/474964-use-of-enoxaparin-in-the-setting-of-warfarin-inducedcalciphylaxis-in-an-esrd-patient-with-a-mechanical-heart-valve 


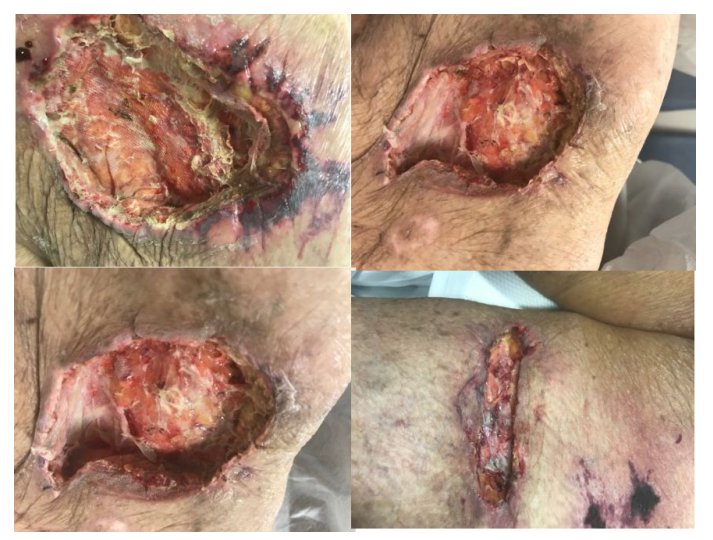

Figure 1. Bilateral lower extremity necrotic ulcers after debridement 


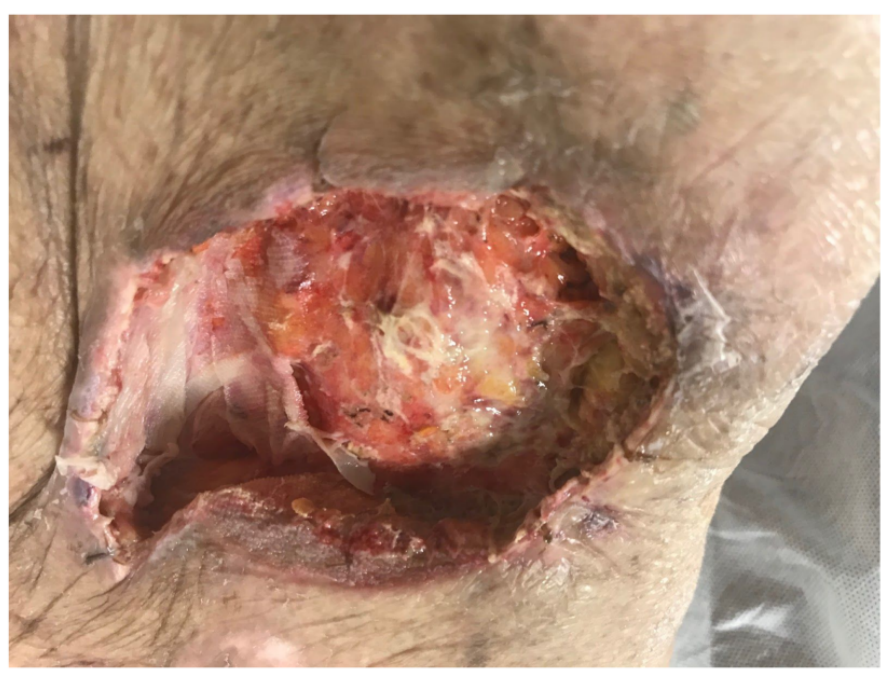

